\title{
The use of Net Promoter Score (NPS) to predict sales growth: insights from an empirical investigation
}

\author{
Sven Baehre ${ }^{1} \cdot$ Michele O'Dwyer $^{1} \cdot$ Lisa O'Malley $^{1} \cdot$ Nick Lee $^{2}$ (i) \\ Received: 31 May 2020 / Accepted: 16 May 2021 / Published online: 5 July 2021 \\ (C) The Author(s) 2021
}

\begin{abstract}
Net Promoter Score (NPS) has been widely adopted by managers as a measure of customer mindset and predictor of sales growth. Over time, practitioners have evolved the use of NPS from its original purpose as a transaction-based customer loyalty metric, towards a metric for tracking overall brand health which includes responses from non-customers. Despite enduring managerial popularity, academics remain skeptical of NPS, citing methodological issues and ongoing concerns with NPS measurement. This study re-visits the use of NPS as a predictor of sales growth by analyzing data from seven brands operating in the U.S. sportswear industry, measured over five years. Our results confirm — within the context of our study — that while the original premise of NPS is reasonable, the methodological concerns raised by academics are valid, and only the more recently developed brand health measure of NPS (using an all potential customer sample) is effective at predicting future sales growth.
\end{abstract}

Keywords Net Promoter Score $\cdot$ Customer mindset $\cdot$ Marketing performance metrics $\cdot$ Brand health $\cdot$ Customer journey $\cdot$ Panel model

\section{Introduction}

In 2003, Reichheld (p. 54) advised managers that Net Promoter Score (NPS) is "the one number you need to grow" in order to increase sales. In the interim many firms have adopted NPS; for example, more than two thirds of Fortune 1000 firms across numerous industries apply NPS to their business (Kaplan, 2016). Although immediately and

John Hulland and Mark Houston served as Editors for this article.

Sven Baehre

sven.baehre@ul.ie

Michele O'Dwyer

michele.odwyer@ul.ie

Lisa O'Malley

lisa.omalley@ul.ie

Nick Lee

nick.lee@wbs.ac.uk

1 Kemmy Business School, University of Limerick, National Technological Park, Limerick, Ireland

2 Warwick Business School, University of Warwick, Scarman Road, Coventry, West Midlands CV4 7AL, UK enduringly popular with managers, NPS was quickly rejected by academia. Researchers identified several methodological concerns with the original NPS study. For example, Reichheld (2003) analyzed past but not future sales growth rates by using simple correlations, and focused on static NPS levels measured at one point in time. These issues, among others identified by critics, rendered the claim made by Reichheld (2003) highly questionable and as such call into question the utility of NPS as a predictor of future sales growth (e.g., Grisaffe, 2007; Sharp, 2008; Shaw, 2008).

As well as the methodological critiques cited above, empirical studies aiming to replicate Reichheld's results have generally failed to do so, and many have found that NPS has no impact on sales growth (Keiningham, Cooil, Andreassen, \& Aksoy, 2007; Morgan \& Rego, 2006). Furthermore, although studies by van Doorn et al. (2013) and Pingitore et al. (2007) did find that NPS can predict sales growth to a certain extent, even these authors appear skeptical of NPS: Pingitore et al. (2007) for example called their study "The Single Question Trap," while van Doorn et al. (2013, p. 317 ) concluded that "the predictive capability of customer metrics, such as NPS, for future sales growth [...] is limited." Overall, it is fair to say that despite some limited support for the predictive value of NPS, the academic perception of NPS is predominantly negative (Bendle et al., 2019). 
Even though academia sends a generally negative message to practitioners about NPS, a significant number of firms continue to use it. This suggests that it is possible that firms have identified conditions under which NPS adds value. With this in mind, it is interesting to note that, although initially introduced as a transaction-based customer loyalty metric, many companies including Apple (Denning, 2011), Best Buy, Delta Airlines (Safdar \& Pacheco, 2019), and GE (Gupta \& Zeithaml, 2006) currently use NPS as a core marketing metric which informs decision making, impacts employee remuneration, and is communicated in earnings reports to investors (Safdar \& Pacheco, 2019). Furthermore, while guidance for managers on to how to use NPS to predict future sales growth has been absent from academic sources, consultancy firms such as Bain \& Company and Satmetrix have stepped in to fill this void, with claims that they have identified the conditions under which NPS should be used (Bendle et al., 2019). One of these specifications is that NPS not only is a transactional customer loyalty metric but also can be thought of as an overall brand health measure that can be used for competitive benchmarking and target setting (e.g., Markey, 2014; Qualtrics, 2020). The key difference between these two uses of NPS is that the original customer loyalty usage of NPS captures data only from current customers right after a direct interaction with the brand, while the newer brand health usage of NPS uses data from all potential customers in the market, and can be collected for competitors as well (Fitzgerald, 2017; Markey, 2014). Notably, this all-customer, brand health use of NPS is considered by practitioners to be closely related to future sales growth (Fitzgerald, 2017). Reichheld and Markey (2011) pick up on this evolved managerial practice and advise that firms should track both types of NPS. However, no academic research has been conducted on NPS as a brand health metric, perhaps due to the early development of a highly negative perception of NPS as a topic for academic study.

This leads to an interesting scenario: While the academic perspective on the utility of NPS as a predictor of future sales growth is generally negative, both academics and practitioners have identified several scenarios as to how NPS should be used beyond Reichheld's (2003) original proposal. However, to date, these scenarios and specifications have yet to be explored in empirical research, highlighting a considerable research gap. This paper aims to close this gap, and in doing so, revisits the utility of NPS as a predictor of future sales growth. We address several of the methodological concerns raised by academic studies (e.g., Grisaffe, 2007; Shaw, 2008) regarding Reichheld's original NPS usage, and also consider how managers have evolved the use of NPS in contemporary practice (e.g., Fitzgerald, 2017; Markey, 2014). Therefore, our study provides new evidence to help answer the following questions: Why have prior studies come to different conclusions regarding the relationship between NPS and sales growth? Is NPS a valid predictor of future sales growth? Are the methodological criticisms of the original NPS study valid? Should NPS be used as a customer loyalty metric, a brand health metric, or not at all? Taken together, we address the broad question of how NPS should be best used by managers, if at all. To answer these questions, we examine NPS within the U.S. sportswear industry. This industry was chosen because metrics such as NPS are better predictors of performance in industries where customers have both short interpurchase cycles (Gruca \& Rego, 2005) and high emotional involvement in the purchase decision (Shaw, 2008). NPS data for seven of the biggest brands in this industry were collected over five years, resulting in a dataset of 193,220 NPS evaluations.

Our nuanced findings suggest some reasons why, despite strong academic criticisms, NPS remains almost ubiquitous in practice, and also show that differences in research methodologies may explain why findings from previous studies have differed. More specifically, our results show that NPS can be a valid predictor of sales growth under certain conditions, but they also confirm critiques of the methodology employed in Reichheld's (2003) original study. Significantly, we demonstrate that NPS has the most predictive value when forecasting sales growth in the near future, and, that managers can maximize the utility of NPS by maintaining a focus on improving NPS rather than on achieving high absolute levels of NPS. We also confirm that only the common managerial practice of using NPS as a measure of brand health, by tracking NPS for all potential customers (e.g., Fitzgerald, 2017; Markey, 2014), has predictive value. This contrasts with the prevailing academic perspective that NPS is a customer loyalty metric, that should be operationalized by tracking NPS only for current customers (e.g., Keiningham, Cooil, Andreassen, \& Aksoy, 2007; Morgan \& Rego, 2006; van Doorn et al., 2013), and confirms findings by Kristensen and Eskildsen (2014) that NPS is not a good measure of loyalty. These findings provide managers with new guidance on how to improve their current practices around NPS, and open up new directions for the academic study of NPS.

The paper proceeds as follows: We provide an overview of the current state of scholarly literature on NPS, and delineate the methodological issues associated with prior NPS studies. Next, we introduce our methodology, paying particular attention to how we address the issues raised in previous studies. This is followed by the presentation and discussion of our results. Finally, we outline implications for theory and practice, and offer directions for future research on NPS and concluding remarks.

\section{Literature review}

\section{The introduction of NPS}

Reichheld introduced NPS in the Harvard Business Review in 2003 as a survey-based metric that excelled in predicting 
future sales growth. As NPS is based on customer responses to one question - "How likely is it that you would recommend [company X] to a friend or colleague?" (Reichheld, 2003, p. 50 - it is simple to capture and calculate. Reichheld (2003, p. 48) considered NPS to be a measure of "intense loyalty" as customers put their reputation on the line when they provide recommendations to friends. Consequently, Reichheld (2003) argued that NPS is more powerful than measuring retention rates or repurchase intent as these metrics are not always tied to loyalty, but can be based on convenience or the lack of alternative products. The answers to the NPS question are given on a scale from 0 to 10 and are grouped into three categories: "Promoter" (customers answering with the highest scores 9 or 10), "Passive" (responses of 7 or 8 ), and "Detractor" (responses below 7). NPS is then calculated simply by taking the difference between "Promoters" and "Detractors" and dividing it by the overall sample sizehence the name "Net Promoter."

\section{Net Promoter Score}

\section{$=\left(\sum\right.$ Promoters $-\sum$ Detractors $) /$ Sample Size}

In the original study, Reichheld (2003) correlated aggregated NPS values and other survey- based metrics (measured between 2001 and 2002) with a three-year sales growth figure (measured between 1999 to 2002) for multiple firms across twelve industries. As NPS showed the strongest correlations with sales growth, Reichheld (2003) concluded that firms can achieve future sales growth by increasing their NPS, and therefore he recommended that managers focus on improving NPS in order to grow sales.

\section{Academic NPS literature}

The premise that NPS can predict sales growth seems to be intuitive: If customers spread positive word-of-mouth among their friends, some of their friends will try the brand and become customers, which will ultimately increase the brand's sales. The positive relationship between other customer mindset metrics, e.g., customer satisfaction, and firm performance is well-established in marketing literature (see the meta-analysis by Otto et al., 2020), and NPS has also been linked successfully to word-of-mouth behavior (Keiningham, Cooil, Aksoy, Andreassen, \& Weiner, 2007; Raasens \& Haans, 2017), increased customer spending (Mecredy et al., 2018), retention intent (Leisen Pollack \& Alexandrov, 2013), and actual retention (de Haan et al., 2015), all of which are important links in the NPS-sales growth chain.

However, while several studies have shown the positive relationship between NPS and customers' intentions and behavior, research on the impact of NPS on sales growth is scarce and has yielded mixed evidence: Apart from
Reichheld's (2003) original study, there are only four academic studies which directly investigate the relationship between NPS and sales growth (see Table 1 for a summary), and none of them confirmed Reichheld's (2003) claim that NPS is a superior predictor of sales growth. The studies by Morgan and Rego (2006) and Keiningham, Cooil, Andreassen, \& Aksoy, (2007) found that NPS had no impact on sales growth, whereas Pingitore et al. (2007) and van Doorn et al. (2013) concluded that NPS is a predictor of sales growth but is not superior to other customer mindset metrics.

\section{Methodological issues in NPS research}

Academic uncertainty regarding Reichheld's (2003) study, and its claim, was further bolstered by a number of articles which point out methodological issues in the calculation of the NPS metric, and/or in Reichheld's (2003) original research design. Concerns regarding the NPS calculation focus on the reduction of response variability through the exclusion of parts of the sample, and the adoption of arbitrary cut-off points (e.g., Grisaffe, 2007; Kristensen \& Eskildsen, 2014). ${ }^{1}$ Methodological concerns around Reichheld's (2003) original research design focus on the use of (1) cross-sectional data rather than longitudinal data (Keiningham, Cooil, Andreassen, \& Aksoy, 2007), (2) correlations, which as the sole method of analysis cannot provide strong evidence of causation (Grisaffe, 2007), and (3) historic sales growth data, which is questionable as a proxy for future sales growth (Grisaffe, 2007; Shaw, 2008).

In evaluating the findings of the existing academic literature on NPS, consideration needs to be given to the fact that a number of these methodological issues are also present in other studies investigating NPS as a predictor of sales growth (see Table 1). Pingitore et al. (2007) replicated the original study using correlations, cross-sectional datasets, and historic sales growth, whereas other researchers adapted the original study: Keiningham, Cooil, Andreassen, and Aksoy (2007) used (partially) longitudinal data, but correlated NPS and sales growth measured for the same period. Furthermore, their study stretches across five industries but is based on a limited number of observations, analyzing a maximum of four firms in each industry and only using longitudinal data (for a maximum of four years) in two industries. ${ }^{2}$ While Keiningham,

\footnotetext{
${ }^{1}$ Interestingly, while these may be considered scientific issues (or "bugs"), they may act as practical "features", given that they are likely to make the calculation and interpretation of the metric much more accessible, particularly when compared with the alternate metrics suggested (e.g., ACSI as proposed by Keiningham, Cooil, Andreassen, \& Aksoy, 2007). Furthermore, the meta-analysis by Otto et al. (2020) has shown that top-box customer satisfaction metrics (which also reduce response variability), are more closely associated with firm performance, and that single-question measures outperform complex metrics such as the ACSI.

${ }^{2}$ The exact sample sizes per analysis are not reported, however, they can be proxied based on the information provided. The numbers stated are a potential maximum number of observations.
} 


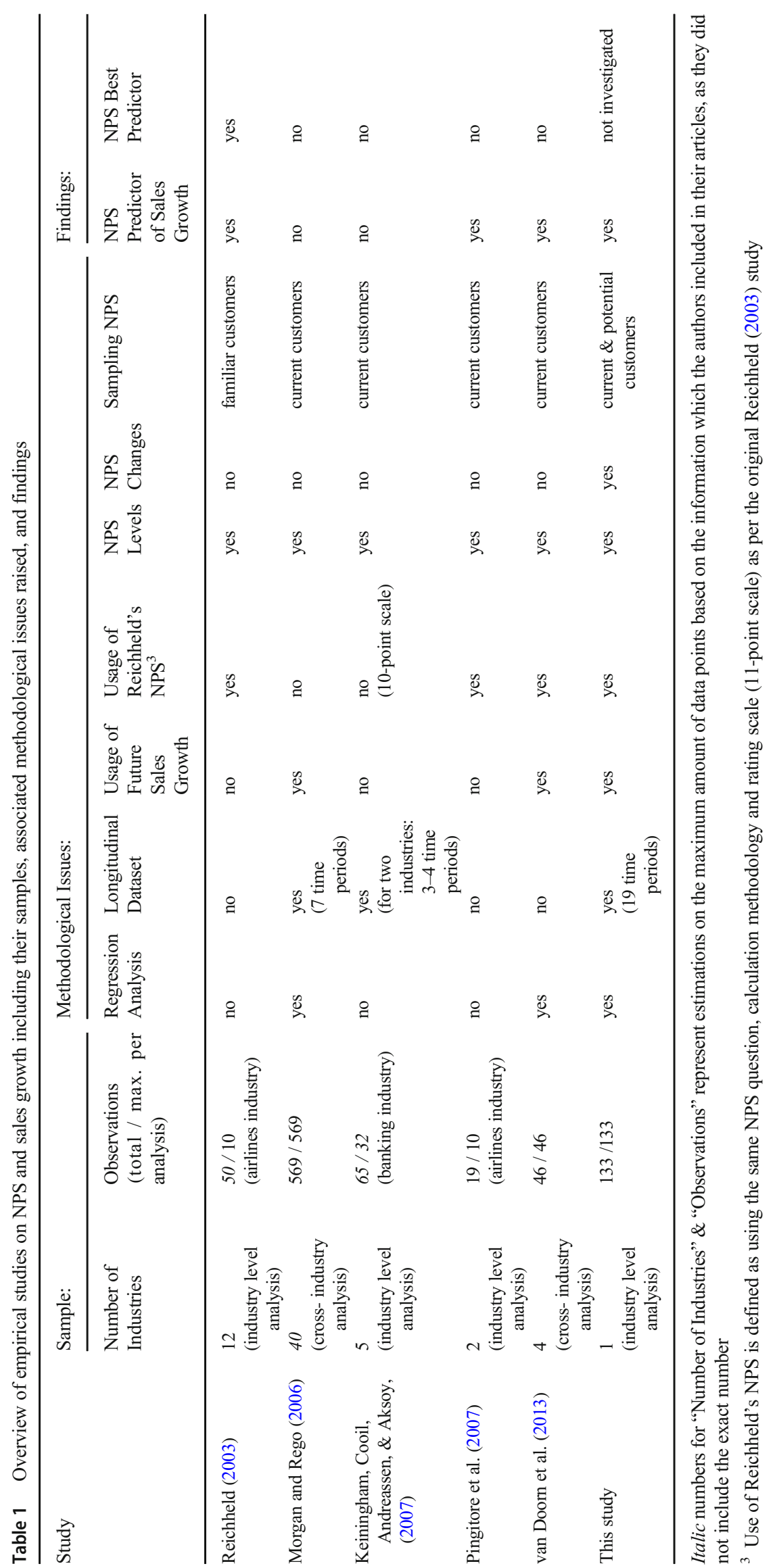


Cooil, Andreassen, \& Aksoy, (2007) concluded that NPS is not a predictor of future sales growth, it needs to be noted that their results for two industries showed medium to strong correlations, which were statistically insignificant. This could be because the sample sizes ( 4 cross-sectional observations in the security systems industry and 32 longitudinal observations in the banking industry) were too small to give adequate power to detect statistically significant effects (Bonett \& Wright, $2000)$. With this in mind, it is also worth noting that Keiningham, Cooil, Andreassen, \& Aksoy, (2007) were unable to detect significant effects of any of the other measures of customer mindset on sales growth in their study (e.g., customer satisfaction or repurchase intent), which have been associated with sales growth in past studies (see Otto et al., 2020). Studies by van Doorn et al. (2013) and Morgan and Rego (2006) analyzed regressions and operationalized future sales growth. While van Doorn et al. (2013) used crosssectional NPS data, Morgan and Rego (2006) used longitudinal data. However, it is uncertain if Morgan and Rego (2006) actually analyzed NPS, as their version of NPS is based on recommendation behavior (instead of intention; see Keiningham et al., 2008).

This diversity in research design and operationalization of NPS - using correlations versus regressions, cross-sectional versus longitudinal data, intention to recommend versus recommendation behavior - combined with often limited numbers of observations, make meaningful comparisons between studies difficult, and also make it difficult to draw strong conclusions regarding the validity of NPS. Additional methodological considerations include time lags, static versus dynamic NPS, and using NPS as a customer loyalty versus a brand health measure.

Time lags Across studies, different time lags were applied; for example, van Doorn et al. (2013) analyzed NPS and future sales growth by comparing time lags of one to three years. They found that a time lag of one year delivered the best results, suggesting that NPS is a better predictor of shortrather than long-term sales growth. This is supported by related studies which also find that customer mindset metrics are better predictors when used for shorter time spans. For example, Morgan and Rego (2006) proposed that customer mindset metrics are good predictors of future firm performance for time lags between one and three quarters, while Williams and Naumann (2011) found the greatest impact was evident when using time lags of one quarter. Summarizing these findings, literature indicates that it is more likely that NPS is an effective predictor of short-term rather than long-term sales growth.

Static levels versus dynamic changes Despite suggesting that improvements in NPS lead to future sales growth, Reichheld's (2003) analysis was based on static NPS levels, which to the best of our knowledge appears to also be the case in all other empirical NPS studies. Grisaffe (2007) argued that a static NPS score taken at one point in time cannot capture information about a dynamic change in sales over time, and thus proposed that NPS should be operationalized as a change as well. Related studies (e.g., Ittner \& Larcker, 1998; Rego et al., 2013) have suggested that results differ when customer satisfaction and firm performance metrics are measured as levels or changes, or when one metric is measured as a level and the other as a change. On this basis we anticipate that changes in NPS are more likely to be a predictor of sales growth, rather than NPS levels.

Customer loyalty versus brand health measure A common approach across all academic studies on NPS and sales growth has been to survey current customers. Indeed, it seems to be logical that a customer can only recommend a company if they have had an experience with it, especially if NPS is considered to be a measure of loyalty. Furthermore, Reichheld (2003) described Enterprise Rent-A-Car's NPS practice in detail as a transactional, real-time survey of its customers. Nevertheless, it is also clear on closer examination that Reichheld (2003) analyzed NPS scores from customers who are familiar with the brand, not just current customers. This is a key difference, as customers can be familiar with a brand even if their experience is not recent, or if their brand knowledge is based on advertisements, endorsements, trials, experiences of friends, or reviews/reports. Hence, Reichheld's (2003) sampling approach appears to be different to that of the follow-up studies. This could potentially be a reason why findings have differed. Indeed, Bendle et al. (2019, p. 217) stated that researchers need to take "all reasonable steps to recreate the NPS score as Reichheld might have estimated it" in order to perform an adequate comparison. Furthermore, whatever Reichheld's original intentions for NPS were, capturing NPS for both current customers and non-customers is now common managerial practice, as consultancies propose this as the optimal approach in how to use NPS for strategic decision making, target setting and competitive benchmarking (e.g., Fitzgerald, 2017; Markey, 2014). Typically, customers are not surveyed directly by individual brands, but through a double-blind survey of multiple brands conducted by research agencies (Reichheld \& Markey, 2011). This measurement of NPS is considered by practitioners to be closely related to future sales growth (Fitzgerald, 2017).

Clearly, measuring NPS for current or all potential customers are two different ideas. Customer journey models (e.g., Court et al., 2009; Lemon \& Verhoef, 2016; Pauwels \& van Ewijk, 2020), which can be split into the stages of prepurchase, purchase, and post-purchase, can help to illustrate the difference. For each of the stages, different metrics can be used to track customer mindset and behavior along the customer journey: During the pre-purchase stage, metrics such as 
brand awareness or consideration are of interest; followed by purchase intent and behavior during the purchase stage (Lemon \& Verhoef, 2016). At the post-purchase stage, the focus is on product usage, customer satisfaction, and loyalty, including recommendation intent and behavior (Court et al., 2009; Lemon \& Verhoef, 2016). All respondents are typically asked initially about their pre-purchase attitudes, and only move on towards the next stage of the questionnaire if they are aware of the brand (and so on). Hence, NPS captured for current customers would capture information only on the ultimate stage of the customer journey, and can be considered to be a measure of customer loyalty; while NPS captured for all potential customers represents an aggregated metric across all stages of the customer journey, as every potential customer answers the NPS question. Therefore, NPS measured for all potential customers could be viewed as a measure of overall brand health, which appears to best describe the current managerial usage of NPS (see Fitzgerald, 2017; Markey, 2014).

While academic studies have not yet explored the validity of NPS as an overall brand health metric by considering this wider sampling approach, relevant research suggests that there are potential advantages in capturing NPS for all potential customers: Katsikeas et al. (2016, p. 14) note that one of the key considerations in assessing customer mindset metrics is whether they are measured for current, or for all potential customers. The inclusion of non- or ex-customers is important as they are on the one hand the main source of negative attitudes towards a brand (East et al., 2011), but on the other hand offer the most potential in terms of growth. Specifically, sales growth can originate from either acquiring new customers or from increasing the lifetime value of existing customers (e.g., Bandyopadhyay \& Martell, 2007; Ittner \& Larcker, 1998; Zeithaml et al., 2006). Hence, NPS measured for all potential customers captures relevant information for both growth sources, whereas NPS measured for current customers does not include any insights on the acquisition of new customers beyond a potential attraction of new customers through wordof-mouth. Therefore, despite the conceptual ambiguity around the original definition of NPS itself, we expect that the brand health use of NPS which is measured for all potential customers, is a better predictor of future sales growth than the customer loyalty usage of NPS, which is measured for current customers.

\section{Methodology}

\section{Empirical context}

Our selection of a suitable research context is driven by the notion that the utility of NPS is almost certainly subject to industry differences (e.g., de Haan et al., 2015; Keiningham, Cooil, Andreassen, \& Aksoy, 2007; Reichheld, 2003) and it is therefore unlikely that NPS (or other customer mindset metrics) could be the "one number you need to grow" (Reichheld, 2003 , p. 54) in all industries. NPS works best in industries where customers are more likely to give recommendations, such as those with high emotional involvement in the purchase decision (Shaw, 2008). Gruca and Rego (2005) also note that customer mindset metrics work particularly well in consumer goods industries where customers have short interpurchase cycles, such as the apparel, athletic shoes, or beer industry. Consequently, we chose to conduct our study in the U.S. sportswear industry, ${ }^{4}$ focusing on seven of the biggest brands, which have a combined market share of twothirds of the branded sportswear market. The dataset tracks the longitudinal development of the brands over five years and was provided by one of the brands.

\section{Data}

NPS data Our sample includes NPS data from 38,644 people, providing 193,220 NPS evaluations for the seven brands researched. The data was collected by a market research firm in accordance with the procedures proposed by Bain \& Company. This ensures that our NPS data is collected in a similar manner to Reichheld's (2003), which is important to ensure comparability, especially since all previous studies on NPS have differed in this regard (see Bendle et al., 2019). Data collection focused on respondents aged between 16 and 30 as this group has the highest sports participation rate (see Sports \& Fitness Industry Association, 2018) and spends almost twice as much annually per capita on sportswear than other people ( $\$ 441$ versus $\$ 236$, based on U.S. data from the market research firm The NPD Group). NPS data were collected using a monthly online survey between 2013 and 2017 from consumers who had purchased sportswear in the previous month. The use of an online survey is appropriate as internet penetration is at 98\% for this age group (Pew Research Center, 2018). Each person was surveyed once and provided feedback on five brands. By controlling for geographies and gender splits, the sample can be considered to be representative of the U.S. population for this age group. The survey included multiple questions and took each respondent approximately $15 \mathrm{~min}$ to complete. Two questions are relevant to this study: (1) Reichheld's (2003) original NPS question and (2) a question asking if respondents had purchased products from each

\footnotetext{
${ }^{4}$ We appreciate that studying a single industry in depth may raise questions of generalizability. However, in choosing to study one industry, we were able to maximize NPS data to explore many different aspects of the use of NPS, which would have been impossible had we a less-detailed dataset across multiple industries. In doing so, we follow the example of numerous recent marketing studies, which focus on maximizing the richness of data from a single industry, and sometimes even a single firm, over collecting less comprehensive data from a broader set of firms or industries, thus gaining heretofore unobtainable insights (e.g., Atefi et al., 2018; Ngobo, 2017; Sanchez et al., 2020; Zhou et al., 2019).
} 
of the brands in the last year. Using these answers, we formed two samples, a current customer sample, and an all potential customers sample-including both current customers and non-customers of each brand - to reflect a customer loyalty and a brand health metric of NPS. For both metrics, NPS is calculated using Reichheld's (2003) NPS formula; based on these static NPS levels, we calculate dynamic changes in NPS by computing the period-over-period difference.

Sales data Sales growth is measured as a percentage change in sales (Morgan \& Rego, 2006; van Doorn et al., 2013). In this study we use sales data from The NPD Group, which tracks self-reported customer purchases per brand and quarter for the sportswear industry. This sales data is used because (1) accounting-based data are largely unavailable and incomparable across all brands, and (2) for comparability with NPS the sales data used should represent sales to end-customers, however, the sales figures reported in this industry are predominantly sales to retailers and not to end-customers. ${ }^{5}$

The NPD Group gathers their sales data by using an online survey, where respondents report their purchase volumes and prices paid. The survey results are extrapolated to produce a full estimate of the sales volume for each brand. The data are available from 2013 up to the first quarter of 2018 for all sportswear brands in the market and are based on approximately 50,000 purchase observations per quarter leading to a representative market coverage. As NPS data are available on a monthly basis, and sales growth information is available on a quarterly basis, we perform our analysis on a quarterly basis (reflecting the approach adopted by Ittner \& Larcker, 1998). ${ }^{6}$ Hence, our final dataset includes data for 19 consecutive quarters for each of the seven brands, leading to a sample size of 133 observations.

Control variables To control for different marketing strategies, brand-specific control variables which impact sales growth and have been utilized as controls in similar studies are included. These controls include pricing (e.g., Jacobson \& Aaker, 1985) and diversification (e.g., Feng et al., 2017; Rego et al., 2013), as price increases and expansions into new categories are established routes used by brands to grow sales. Therefore, we include average selling price and the number of sports categories in which a brand is active as control variables.

\footnotetext{
${ }^{5}$ Despite the issues outlined, we analyzed the comparability of the sales data used with actual reported sales figures for the five brands where annual sales data is publicly reported. However, for four of the brands the data covers not only the U.S. but also North America, and for the fifth brand the available data covers the entire Americas. Nevertheless, we find that absolute sales numbers $(r=.997)$ and period-over-period changes $(r=.930)$ are highly correlated across these five brands.

${ }^{6}$ The aggregation from monthly to quarterly NPS happened by calculating the NPS values considering all answers during the quarter. As monthly sample sizes were kept constant, similar NPS would have been obtained by averaging the monthly values.
}

Following best practice examples (e.g., Feng et al., 2017; Shi et al., 2018), we include a lagged version of sales growth as well. Otto et al. (2020) also noted that researchers should control for industry dynamics in models which investigate the relationship of customer mindset metrics and firm performance by considering market growth and industry concentration. We follow their suggestion and include quarter-overquarter market growth (measured in percent) and the Herfindahl-Hirschman Index (HHI) which is the most common measure of industry concentration (e.g., Morgan \& Rego, 2006; Rego et al., 2013). All data points were derived from the sales dataset.

\section{Empirical model}

To analyze the relationship between NPS and future sales growth we built a model that uses sales growth as the dependent variable, and NPS and the control variables as independent variables. To capture if NPS predicts future sales growth, NPS variables need to be lagged. Studies suggest that it is more likely that NPS predicts short term sales growth (e.g., Morgan \& Rego, 2006; van Doorn et al., 2013; Williams \& Naumann, 2011) therefore we adopted the shortest time lag possible, lagging NPS by one quarter; similarly, we also lag all control variables (Morgan \& Rego, 2006). Two different models are used in our analysis: Model 1 (Eq. 1), similar to prior NPS research, uses static NPS levels while Model 2 (Eq. 2) uses NPS changes and also changes in (most of) the control variables (similar to the approach by Rego et al., 2013). This specification enables us to explore if high absolute levels of NPS, or improvements in NPS, are associated with sales growth. The models are specified as follows:

$$
\begin{aligned}
& \text { Sales Growth }_{\mathrm{i}(\mathrm{t}+1)}= \beta_{0}+\beta_{1} \text { NPS }_{\mathrm{i}(\mathrm{t})} \\
&+\beta_{2} * \text { Sales Growth }_{\mathrm{i}(\mathrm{t})} \\
&+\beta_{3} * \text { Average Selling Price } \\
& \mathrm{i}(\mathrm{t}) \\
&+\beta_{4} * \text { Number of Categories }_{\mathrm{i}(\mathrm{t})} \\
&+\beta_{5} * \text { Market Growth }_{(\mathrm{t})} \\
&+\beta_{6} * \mathrm{HHI}_{(\mathrm{t})}+\mathrm{v}_{\mathrm{i}}+\varepsilon_{\mathrm{i}(\mathrm{t})}
\end{aligned}
$$

Sales Growth G(t+1) $=\beta_{0}+\beta_{1} * \Delta \mathrm{NPS}_{\mathrm{i}(\mathrm{t})}$

$$
\begin{aligned}
& +\beta_{2} * \text { Sales Growth }_{\mathrm{i}(\mathrm{t})} \\
& +\beta_{3} * \Delta \text { Average Selling } \text { Price }_{\mathrm{i}(\mathrm{t})} \\
& +\beta_{4} * \Delta \text { Number of Categories }_{\mathrm{i}(\mathrm{t})} \\
& +\beta_{5} * \text { Market Growth }_{(\mathrm{t})} \\
& +\beta_{6} * \Delta \mathrm{HHI}_{(\mathrm{t})}+v_{\mathrm{i}}+\varepsilon_{\mathrm{i}(\mathrm{t})}
\end{aligned}
$$


where $\mathrm{i}$ stands for brand and $\mathrm{t}$ for time (quarter), $\beta$ denotes the regression coefficients, $v_{i}$ represents brand-specific non-observable, time-invariant characteristics, and $\varepsilon_{i(t)}$ is the error term which can vary across both time and brands. In order to address whether NPS performs better as a customer loyalty or brand health metric, we ran both models twice, once with the customer loyalty metric (current customer sample), and once with the brand health metric (all potential customer sample) of NPS.

Our balanced panel dataset tracks the same seven brands over time. Because this nested panel data structure violates key assumptions of OLS regressions (e.g., Habel \& Klarmann, 2015), we estimated our models using a random effects model-also known as an error components model (Wallace \& Hussain, 1969) or variance components model (Amemiya, 1971). Random effects regressions are designed to analyze panel datasets by considering heterogeneity across the different brands and their longitudinal development (Baltagi, 2013). Bell et al. (2019) point out that commonly used random effects models assume that the within (timevarying) effect and the between (firm specific or also timeinvariant) effect are equal, which is usually not the case. Therefore, we explicitly included in our model separate within effects (represented by $\varepsilon_{\mathrm{i}(\mathrm{t})}$ ), such as changing spending on advertising, and between effects (operationalized as $v_{\mathrm{i}}$ ), such as distribution strategy, which is not likely to change in the observed time frame (Baltagi, 2013).

\section{Results}

\section{Model free evidence}

The analysis commenced with a model free approach (see Table 2). In analyzing descriptive statistics of our data, we find that the mean level is 43.26 for the customer loyalty metric of NPS, while it is -3.22 for the brand health metric. Taking a closer look into the differences of the NPS levels, we also find that the standard deviation for customer loyalty NPS (20.61) is lower than for brand health NPS (34.44), which can be explained due to the fact that the maximum (79.7) and minimum customer loyalty NPS (.8) differ less than for brand health NPS (71.2 vs. -45.3). The differences across the metrics and samples, support East et al.'s (2011) findings, that non- or ex-customers of a brand are the largest source of negative attitude towards brands, suggesting that metrics which are only based on responses from current customers differ less and are biased upward. However, current customers change their mind about brands more than potential customers, illustrated by the higher means of NPS changes for the current customer sample (.56) than for the potential customer sample (.17).

The correlation analysis (see also Table 2) demonstrates that NPS measures are not correlated with either current or future sales growth. Hence, our results differ from the findings by Reichheld (2003) and Pingitore et al. (2007), who found high correlations between static levels of NPS and historic sales growth. This could be explained due to the fact that our correlation analysis is not directly comparable with their approaches, as their sample sizes are significantly smaller and observe longer, but prior, growth periods. Instead, our findings support Keiningham, Cooil, Andreassen, and Aksoy (2007), who used a similar correlation estimation approach to ours, finding no correlation between static levels of NPS and current sales growth.

Given that the correlation analysis did not detect a significant relationship between any measure of NPS and sales growth, we performed another model free analysis. We compared the average sales growth for all quarters where NPS levels/NPS changes are above and below their respective averages. The results (see Fig. 1) show that future sales growth is on average higher in quarters where NPS changes are high

Table 2 Means, standard deviations, and correlations of variables

\begin{tabular}{|c|c|c|c|c|c|c|c|c|c|c|c|c|c|c|c|c|}
\hline & \multirow[t]{2}{*}{ Variable } & \multirow[t]{2}{*}{ Mean } & \multirow[t]{2}{*}{ Standard Deviation } & \multicolumn{13}{|c|}{ Correlations } \\
\hline & & & & 1 & 2 & 3 & 4 & 5 & 6 & 7 & 8 & 9 & 10 & 11 & 12 & 13 \\
\hline 1 & Sales Growth $_{\mathrm{i}(t+1)}$ & 6.22 & 31.40 & 1.000 & & & & & & & & & & & & \\
\hline 2 & Sales Growth $\mathrm{i}(\mathrm{t})$ & 6.76 & 32.25 & -.446 & 1.000 & & & & & & & & & & & \\
\hline 3 & $\mathrm{NPS}_{\mathrm{i}(\mathrm{t})}($ Customer Loyalty $)$ & 43.26 & 20.61 & .026 & .004 & 1.000 & & & & & & & & & & \\
\hline 4 & $\Delta \mathrm{NPS}_{\mathrm{i}(\mathrm{t})}($ Customer Loyalty) & .56 & 9.93 & .095 & -.069 & .223 & 1.000 & & & & & & & & & \\
\hline 5 & $\mathrm{NPS}_{\mathrm{i}(\mathrm{t})}($ Brand Health $)$ & -3.22 & 34.44 & -.039 & -.027 & .842 & -.012 & 1.000 & & & & & & & & \\
\hline 6 & $\Delta \mathrm{NPS}_{\mathrm{i}(\mathrm{t})}($ Brand Health) & .17 & 3.99 & .107 & .097 & .139 & .432 & .089 & 1.000 & & & & & & & \\
\hline 7 & Average Selling Price $_{i(t)}$ & 25.52 & 7.50 & .025 & .133 & .335 & .051 & .109 & .161 & 1.000 & & & & & & \\
\hline 8 & $\Delta$ Average Selling Price ${ }_{i(t)}$ & .12 & 4.27 & .155 & -.200 & -.014 & -.077 & .005 & -.114 & -.331 & 1.000 & & & & & \\
\hline 9 & Number of Categories ${ }_{i(t)}$ & 6.38 & 3.88 & -.083 & -.042 & .375 & -.026 & .686 & .021 & -.464 & .034 & 1.000 & & & & \\
\hline 10 & $\Delta$ Number of Categories ${ }_{i(t)}$ & -.04 & 1.17 & .181 & -.134 & -.026 & -.230 & .011 & -.216 & -.001 & .035 & -.140 & 1.000 & & & \\
\hline 11 & Market Growth $(t)$ & 3.92 & 16.12 & .226 & .341 & -.020 & -.003 & -.004 & .042 & -.062 & .128 & .054 & -.089 & 1.000 & & \\
\hline 12 & $\mathrm{HHI}_{(\mathrm{t})}$ & 453.98 & 62.59 & .082 & .379 & .012 & -.007 & .007 & .050 & -.062 & .127 & .055 & -.159 & .915 & 1.000 & \\
\hline 13 & $\Delta \mathrm{HHI}_{(\mathrm{t})}$ & -4.29 & 95.47 & .212 & -.447 & .005 & .042 & -.002 & .001 & .015 & -.086 & -.050 & .266 & -.634 & -.775 & 1.000 \\
\hline
\end{tabular}

Bold values are significant at the $p<.05$ level; $N=133$ ( 7 brands $* 19$ quarters) 
Fig. 1 Analysis of average future sales growth for quarters where NPS levels / changes are above / below their respective average value

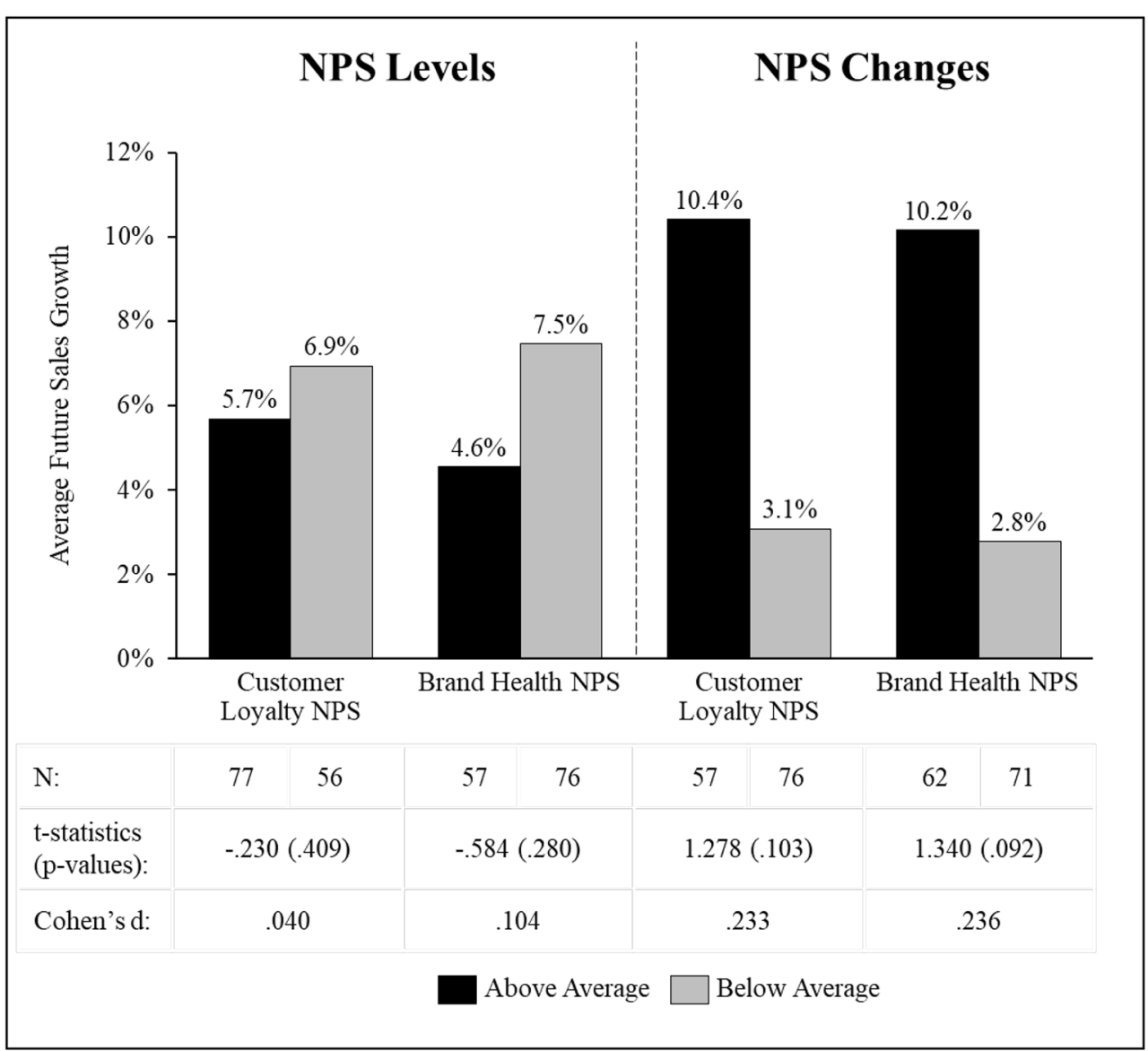

(customer loyalty NPS $10.4 \%$, brand health NPS $10.2 \%$ ), while it is comparatively low in quarters where NPS changes are below average (customer loyalty NPS $3.1 \%$, brand health NPS $2.8 \%$ ). In contrast, we find that average sales growth is similar when NPS levels are above (customer loyalty NPS 5.7\%, brand health NPS $4.6 \%$ ) or below (customer loyalty NPS $6.9 \%$, brand health NPS $7.5 \%$ ) average NPS levels, with a tendency for lower sales growth when NPS levels are higher.

In order to analyze if these differences are also statistically significant, we performed a one-sided t-test and calculated Cohen's d (Cohen, 1988), controlling for different standard deviations by using a pooled standard deviation (Rosnow \& Rosenthal, 1996). While the ttests provide marginally significant findings for NPS changes across both NPS metrics $(p \sim .1$, see Fig. 1), the obtained values for Cohen's $d$ suggest that there are small differences across the averages for NPS changes while the differences for NPS levels are more likely to be only "noise" (Cohen, 1988, p. 25). Overall, this analysis provides initial indications that brands can grow their sales by increasing their NPS, however this does not necessarily imply that high NPS levels lead to sales growth.

\section{Model results}

Overall, the results of our random effects model show that NPS can be a significant, positive predictor of future sales growth (see Table 3 ). However, at the same time, the results suggest that the methodological criticisms of Reichheld's (2003) study, (e.g., Grisaffe, 2007; Shaw, 2008), and the way NPS is used in practice (e.g., Fitzgerald, 2017; Markey, 2014), are of concern when considering how to obtain meaningful results from NPS data analysis.

Specifically, we only find the brand health use of NPS in Model 2 to be significant when it is operationalized as changes ( $\beta=1.458, p<.01$ ), and also find the highest increase in model fit here $\left(\operatorname{adj} . \mathrm{R}^{2}=.350\right)$ versus the other three estimated models, but also compared to a base model that did not contain any of the NPS metrics at all (adj. $\mathrm{R}^{2}=.322$, not reported in Table 3). This demonstrates that it is important to distinguish between static NPS levels and dynamic NPS changes, suggesting that brands who improve their NPS tend to grow their sales in the future. As NPS levels are not significant in Model 1 , it also implies that brands with high levels of NPS will not automatically be able to grow their sales if they do not improve their NPS. Our findings also suggest that in growing sales, NPS is best considered to be a measure of brand health 
Table 3 Results of the main models investigating the relationship between NPS and future sales growth

\begin{tabular}{|c|c|c|c|c|}
\hline \multirow{3}{*}{ Model 1} & \multicolumn{2}{|c|}{ Customer Loyalty NPS } & \multicolumn{2}{|c|}{ Brand Health NPS } \\
\hline & \multicolumn{4}{|c|}{ Sales Growth $\mathrm{i}(\mathrm{t}+1)$} \\
\hline & Beta & S.E. & Beta & S.E. \\
\hline NPS $_{i(t)}$ & .159 & .215 & .012 & .252 \\
\hline Sales Growth $\mathrm{i}(\mathrm{t})$ & -.555 & $.071 * * *$ & -.558 & $.071 * * *$ \\
\hline Average Selling Price $_{i(t)}$ & .665 & .519 & .811 & .547 \\
\hline Number of Categories $_{i(t)}$ & -1.530 & 1.340 & -1.685 & 1.691 \\
\hline Market Growth $_{(t)}$ & 1.822 & $.793 * *$ & 1.788 & $.786 * *$ \\
\hline $\mathrm{HHI}_{(\mathrm{t})}$ & -.270 & .205 & -.259 & .203 \\
\hline $\mathrm{R}^{2}$ & .354 & & .353 & \\
\hline adj. $R^{2}$ & .323 & & .322 & \\
\hline \multirow[t]{2}{*}{ Model 2} & \multicolumn{4}{|c|}{ Sales Growth $\mathrm{i}(\mathrm{t}+\mathbf{1})$} \\
\hline & Beta & S.E. & Beta & S.E. \\
\hline$\Delta$ NPS $_{i(t)}$ & .189 & .236 & 1.458 & $.560 * * *$ \\
\hline Sales Growth $\mathrm{i}(\mathrm{t})$ & -.525 & $.073 * * *$ & -.544 & $.072 * * *$ \\
\hline$\Delta$ Average Selling Price $i(t)$ & -.252 & .499 & -.136 & .486 \\
\hline$\Delta$ Number of Categories ${ }_{i(t)}$ & 2.813 & 1.878 & 3.275 & $1.811 *$ \\
\hline Market Growth $_{(\mathrm{t})}$ & 1.252 & $.391 * * *$ & 1.226 & $.388 * * *$ \\
\hline$\Delta \mathrm{HHI}_{(\mathrm{t})}$ & .114 & $.067 *$ & .101 & .066 \\
\hline $\mathrm{R}^{2}$ & .351 & & .380 & \\
\hline $\operatorname{adj} . R^{2}$ & .320 & & .350 & \\
\hline
\end{tabular}

and measured for all potential customers, implying that brands must not only influence the mindset of current customers, they need to improve the mindset of all potential customers, including non-customers.

Two of the control variables are significant across all models and samples, and the direction of their effects is in line with previous research. Market growth has a significant impact on future sales growth which implies, as the $\beta$ coefficients are above 1 (1.226 to 1.822$)$, that the seven brands in our sample are able to outgrow the market consistently. Furthermore, we find a significant negative carry-over impact of current sales growth on future sales growth ( -.525 to -.558$)$ which is similar to the findings by comparable studies (e.g., Ittner \& Larcker, 1998) implying that brands face difficulties in maintaining sales growth over time. Additionally, we find a significant effect of changes in categories on future sales growth in Model 2 (brand health NPS) suggesting that brands can grow their sales by expanding into new sports categories.

We also applied statistical tests to Model 2 (brand health NPS) to confirm the appropriateness of the model and the estimation techniques utilized. We performed the BreuschGodfrey test for (first order) serial-correlation, and the Breusch-Pagan test to establish that there is no heteroscedasticity (see Baltagi, 2013). The tests showed that there is no serial-correlation (Breusch-Godfrey test: $p=.752$ ) and that there is no issue with heteroscedasticity (Breusch-
Pagan test: $p=.437$ ). Furthermore, we explored (as proposed by Bell et al., 2019) the difference between within and between effects for all models using the Hausman-test. The Hausman test is commonly used as a general test to determine whether a random effects model or a fixed effects model should be used, but more specifically it tests for the equality of the within and between effects (Bell et al., 2019). The results of the Hausman-test confirm for Model $2(p<.05$ for both NPS measures) that the within and between effects are unequal and need to be modeled separately. In contrast, the Hausman-test for Model 1 demonstrated no difference in the within and between effects ( $p>.8$ for both NPS measures). While these results do not necessarily require the use of a fixed-effect model or a more simplistic random effects model (which assumes both effects to be equal-see Bell et al., 2019), we re-estimated Model 1 for both NPS metrics by using these two alternative estimation techniques. However, the results of these additional analyses are not fundamentally different from our initial results and confirmed that NPS levels are not predictors of future sales growth.

To explore if changes in NPS can explain sales growth, we need to address whether our model explains differences in sales growth within a brand or between brands. Therefore, we focus on the within variance of our model which describes how much the variables utilized in our model, including NPS, explain sales growth of each brand individually over time. We 
follow a similar approach to that used by Hanchane and Mostafa (2012) by analyzing the share of the within effect in the overall variation. In Model 2 (using the brand health metric of NPS) $90.7 \%$ of the variation can be explained by variations within the brand over time (within effect 336.28 , between effect 34.34), hence, the model explains within brand variation appropriately.

\section{Additional analyses}

Time lags Our results suggest additional analytical possibilities. In exploring our assumption that NPS is a more effective predictor of sales growth for short time lags, we modified Model 2 by substituting the one-quarter time lag for NPS (and the control variables) with time lags of two- and threequarters (longer time lags were not considered as the number of observations decreases drastically per additional quarter). The results of these models show no significant findings for either NPS metric. We also explored the NPS relationship with current sales growth by using a non-lagged NPS variable (and non-lagged variants of the control variables, except for past sales growth) in Model 2, and find no significant results. Hence, while we find evidence that NPS is a predictor of future sales growth, our findings suggest that it is only a valid predictor for short time lags of one quarter.

NPS and sales levels As static point levels of NPS do not predict future sales growth, we explored if NPS point levels could be associated with future point levels of sales. Therefore, we modified our models by substituting sales growth with market share as a representation of absolute sales levels. The results (see Table 4) of Model 1 for the brand health measure of NPS provide significant results $(\beta=.050, p<.01)$ demonstrating that static NPS levels have a positive effect on future market share, while the results for the customer loyalty measure are not significant $(p=.726)$. In Model 2 across both NPS metrics, NPS changes are not predictors of future market share. In summary, changes of NPS are a predictor for future sales growth, while point levels of NPS are predictive of future point sales levels.

The role of non-customers Based on our analysis the brand health version of NPS emerges as the only predictor of future sales growth, suggesting that in order to grow brands need to influence the mindset of both current and non-customers. To explore this further, and to understand which brand health NPS components drive future sales growth, we performed additional analyses. Initially we explored NPS measured for non-customers only as a predictor of future sales growth (since if this were the case, managers could focus their research efforts on one specific group and reduce sampling costs). Using NPS for those who have not been a recent customer of the brand (by replacing the NPS variables used in Model 2 with changes in NPS for noncustomers) we developed an iteration of Model 2. In here, we
Table 4 Results of models investigating the relationship between NPS and future market share

Customer Loyalty Brand Health NPS
NPS

\begin{tabular}{|c|c|c|c|c|}
\hline \multirow[t]{2}{*}{ Model 1 (modified) } & \multicolumn{4}{|c|}{ Market Share $_{i(t+1)}$} \\
\hline & Beta & S.E. & Beta & S.E. \\
\hline NPS $_{i(t)}$ & .002 & .007 & .050 & $.013 * *$ \\
\hline Market Share $_{\mathrm{i}(\mathrm{t})}$ & .118 & .090 & .020 & .090 \\
\hline Average Selling Price $_{\mathrm{i}(\mathrm{t})}$ & .021 & .018 & .010 & .018 \\
\hline Number of Categories $_{i(t)}$ & .080 & .060 & .057 & .058 \\
\hline Market Growth $(\mathrm{t})$ & .014 & .015 & .021 & .016 \\
\hline $\mathrm{HHI}_{(\mathrm{t})}$ & -.005 & .004 & -.006 & .004 \\
\hline $\mathrm{R}^{2}$ & .064 & & .159 & \\
\hline $\operatorname{adj} . R^{2}$ & .020 & & .118 & \\
\hline \multirow[t]{2}{*}{ Model 2 (modified) } & \multicolumn{4}{|c|}{ Market Share $_{i(t+1)}$} \\
\hline & Beta & S.E. & Beta & S.E. \\
\hline$\Delta$ NPS $_{i(t)}$ & -.004 & .007 & .020 & .016 \\
\hline Market Share $_{i(t)}$ & .154 & $.088^{*}$ & .143 & .088 \\
\hline$\Delta$ Average Selling Price $_{i(t)}$ & -.003 & .014 & .001 & .014 \\
\hline$\Delta$ Number of Categories ${ }_{i(t)}$ & -.064 & .053 & -.044 & .052 \\
\hline Market Growth (t) & .013 & .009 & .012 & .009 \\
\hline$\Delta \mathrm{HHI}_{(\mathrm{t})}$ & .005 & $.002 * * *$ & .005 & $.001 * *$ \\
\hline $\mathrm{R}^{2}$ & .094 & & .104 & \\
\hline $\operatorname{adj} . R^{2}$ & .050 & & .061 & \\
\hline
\end{tabular}

find that it is not sufficient to track NPS for current noncustomers only, as this variable is found to be not significant $(p=.215$, see Table 5$)$.

Based on these results, it becomes evident that the role of non-customers is not the only driver of the predictive capabilities of brand health NPS, therefore we analyzed the different components of brand health NPS by including them individually in our analysis. Intuitively, brand health NPS consists of NPS as measured for current customers, and also current noncustomers. However, these measurements are not sufficient to de-construct brand health NPS given that the latter is actually more reflective of a weighted average by share of customers / non-customers rather, than a simple average of the NPSs of these two groups. ${ }^{7}$ To analyze if it is sufficient to understand the interplay between the NPSs measured for the different groups, or if the share of customers ${ }^{8}$ plays a role in future sales

\footnotetext{
${ }^{7}$ Consider the following illustration: if NPS for non-customers is 5.0 and for current customers it is 50.0, the brand health NPS would be 27.5 if one were to calculate a simple average (or of course if both customer groups are equal in size). However, if for example the actual share of noncustomers is $80 \%$, the average weighted by share of customer would change to 14.0. This clearly shows that it is important not only to consider the NPS for each of the groups, but also the ratio between them.

${ }^{8}$ Share of customers is calculated by dividing the sample size of NPS for current customers by the brand health NPS sample size.
} 
Table 5 Results of models investigating the role of NPS from current non-customers and share of customers

\begin{tabular}{|c|c|c|c|c|c|c|}
\hline \multirow[t]{2}{*}{ Model 2 (modified) } & \multicolumn{6}{|c|}{ Sales Growth $_{\mathrm{i}(\mathrm{t}+1)}$} \\
\hline & Beta & S.E. & Beta & S.E. & Beta & S.E. \\
\hline$\Delta$ NPS $_{i(t)}$ Non-Customers & .482 & .389 & .457 & .391 & .991 & $.496 * *$ \\
\hline$\Delta$ NPS $_{i(t)}$ Current Customers & & & .162 & .237 & .160 & .235 \\
\hline$\Delta$ Share of Customers ${ }_{i(t)}$ & & & & & .945 & $.546 *$ \\
\hline Sales Growth ${ }_{i(t)}$ & -.539 & $.073 * * *$ & -.535 & $.074 * * *$ & -.539 & $.073 * * *$ \\
\hline$\Delta$ Average Selling Price ${ }_{i(t)}$ & -.272 & .492 & -.220 & .499 & -.193 & .496 \\
\hline$\Delta$ Number of Categories $\mathrm{i}(\mathrm{t})$ & 2.377 & 1.822 & 2.680 & 1.879 & 2.673 & 1.864 \\
\hline Market Growth $_{(t)}$ & 1.245 & $.400 * * *$ & 1.236 & $.401 * * *$ & 1.252 & $.395 * * *$ \\
\hline$\Delta \mathrm{HHI}_{(\mathrm{t})}$ & .112 & .069 & .111 & .069 & .115 & $.068^{*}$ \\
\hline $\mathrm{R}^{2}$ & .354 & & .356 & & .371 & \\
\hline $\operatorname{adj} . R^{2}$ & .323 & & .320 & & .331 & \\
\hline
\end{tabular}

growth, we estimated two additional models (both modifications of Model 2). In the second iteration of Model 2 we used changes in NPS obtained for current customers and current non-customers as two individual metrics, and in the third iteration we added period-over-period changes in share of customers.

The results (which can also be found in Table 5), show that the second iteration (testing the assumed straight average calculation across both scores) produces non-significant findings, while the third iteration demonstrates that NPS measured for current non-customers and the share of customers, are both positively related to future sales growth. This confirms that it is important to understand brand health NPS as weighted average by shares of customers/non-customers. Although this is not unexpected, we find that even in this model, NPS measured for current customers does not have a direct impact on sales growth. While it seems to be important to maintain customers (otherwise the share of customers would decrease) current customers' NPS is not directly connected to sales growth. This provides support to suggestions that NPS is not a good measure of customer loyalty (Kristensen \& Eskildsen, 2014), therefore we advise managers to track the proposed brand-health NPS.

Brand health NPS versus other customer mindset metrics The above analysis confirmed that brands should focus on using brand health NPS as a predictor of future sales growth. While the brand health usage of NPS does not provide information as illustrating where in the customer journey a brand has problems, it provides - analogous to the common use of body temperature being used to indicate the general presence/ absence of infection in medicine (Grisaffe, 2007) - an aggregated point of view on the customer mindset across all customers. Even so, it must be asked whether NPS, when used in this way, captures anything more than other customer mindset metrics when they are based on answers from all potential customers, since it seems to be intuitive that non-customers would respond to the NPS question in the same way as they would to other customer mindset questions. If this was the case, there would be little additional value in measuring NPS instead of using other customer mindset questions, given that significant results only occur when the analysis includes all potential customers.

To test this assumption, we compared NPS with three other customer mindset metrics along the customer journey which are usually captured for all potential customers: Brand awareness and brand consideration represent the pre-purchase phase, while purchase intent is included as a measure for the purchase phase of the customer journey. NPS itself represents a measure of the final post-purchase phase. Average scores were calculated for both brand awareness, which is based on a 5-point brand awareness question (ranging from "I feel like I know a lot about the brand." to "I've never heard of the brand."), and brand consideration, which is based on a 6point scale (ranging from "It's the only brand I would consider purchasing." to "I'd never consider wearing this brand."). For purchase intent, we used a measure which asks, if a customer was going to buy a sportswear article now, which brand (single mention) would they buy? The percentage of people who responded with the respective brand was calculated.

We next analyzed the correlations between changes in NPS with changes in these other customer mindset metrics. The correlation analysis (see Table 6) shows that while there are high correlations between changes in NPS and changes in brand awareness (.551) and brand consideration (.671), suggesting a common underlying favorability, they are far from being equal. Apparently, these different questions capture different information even if a number of respondents might not be familiar with a brand. 
Table 6 Correlations of additional customer mindset metrics

\begin{tabular}{|c|c|c|c|c|c|}
\hline & \multirow[t]{2}{*}{ Variable } & \multicolumn{4}{|c|}{ Correlations } \\
\hline & & 1 & 2 & 3 & 4 \\
\hline 1 & $\Delta \mathrm{NPS}_{\mathrm{i}(\mathrm{t})}($ Brand Health $)$ & 1.000 & & & \\
\hline 2 & $\Delta$ Brand Awareness $_{\mathrm{i}(\mathrm{t})}($ Brand Health $)$ & .551 & 1.000 & & \\
\hline 3 & $\Delta$ Brand Consideration $_{\mathrm{i}(\mathrm{t})}($ Brand Health) & .671 & .537 & 1.000 & \\
\hline 4 & $\Delta$ Purchase Intent ${ }_{\mathrm{i}(\mathrm{t})}($ Brand Health) & .320 & .224 & .337 & 1.000 \\
\hline
\end{tabular}

Bold values are significant at the $p<.05$ level; $\mathrm{N}=133$ ( 7 brands $* 19$ quarters)
As the metrics capture different information, we aimed to validate if NPS or any of the other metrics carries more valuable information in predicting future sales growth. Therefore, we modified Model 2 by exchanging the NPS variable with these additional metrics, and estimated each model for the potential customer sample. The results of this analysis (see Table 7) show that changes in brand awareness $(\beta=1.199$, $p<.05)$, brand consideration $(\beta=.801, p<.01)$, and purchase intent $(\beta=3.893, p<.1)$ are all predictors of future sales growth. To analyze if one of the metrics is the best predictor of future sales growth, we focused on model fit improvements (similar to the approach by Morgan \& Rego, 2006). We find that NPS and brand consideration are equally good predictors of sales growth as the respective models have equal model fits (adj. $\mathrm{R}^{2}=.350$ ), and that they outperform brand awareness $\left(\right.$ adj. $\left.\mathrm{R}^{2}=.345\right)$ and purchase intent $\left(\operatorname{adj} . \mathrm{R}^{2}=.331\right)$.

In summary, individuals - regardless of whether they are customers of a brand - respond differently to the four customer mindset questions along the consumer journey (even if there is a common underlying favorability), and thus each of the metrics used carries different information. Nevertheless, when these metrics are measured for all potential customers, they all provide insights into future sales growth. In this regard, NPS and brand consideration offer similar predictions, even if the metrics differ from each other. Although it was never the intention of our study to confirm Reichheld's (2003) claim that NPS is the best predictor of future sales growth, it is worth noting that our results provide some evidence that NPS is a better predictor of future sales growth than brand awareness and purchase intent. However, we do not believe these findings are sufficient to justify the view that NPS is the best predictor, especially as NPS behaves similarly to brand consideration in our analysis.

\section{Discussion}

The results of our study provide answers to the five research questions posed in the introduction: first, our results suggest that the ambiguity of previous NPS studies could be explained by a divergence of research approaches. Second, our study shows that NPS can be a valid predictor of future sales growth in an appropriate market setting (in this case, the U.S. sportswear industry). Third, by testing different modelling,

Table 7 Results of the models investigating the relationship between changes inalternative customer mindset metrics (measured for all potential customers) andfuture sales growth

\begin{tabular}{|c|c|c|}
\hline \multirow[t]{2}{*}{ Model 2 (modified) } & \multicolumn{2}{|c|}{ Sales Growth ${ }_{i(t+1)}$} \\
\hline & Beta & S.E. \\
\hline$\Delta$ Brand Awareness $_{i(t)}$ & 1.199 & $.497 * *$ \\
\hline Sales Growth $\mathrm{i(t)}$ & -.520 & $.072 * * *$ \\
\hline$\Delta$ Average Selling Price ${ }_{i(t)}$ & -.394 & .485 \\
\hline$\Delta$ Number of Categories $i(t)$ & 3.489 & $1.841 *$ \\
\hline Market Growth $_{(\mathrm{t})}$ & 1.229 & $.388 * * *$ \\
\hline$\Delta \mathrm{HHI}_{(\mathrm{t})}$ & .096 & .067 \\
\hline $\mathrm{R}^{2}$ & .375 & \\
\hline $\operatorname{adj} . R^{2}$ & .345 & \\
\hline \multirow[t]{2}{*}{ Model 2 (modified) } & \multicolumn{2}{|c|}{ Sales Growth ${ }_{i(t+1)}$} \\
\hline & Beta & S.E. \\
\hline$\Delta$ Brand Consideration $_{\mathrm{i}(\mathrm{t})}$ & .801 & $.307 * * *$ \\
\hline Sales Growth $_{\mathrm{i}(\mathrm{t})}$ & -.530 & $.071 * * *$ \\
\hline$\Delta$ Average Selling Price ${ }_{i(t)}$ & -.259 & .482 \\
\hline$\Delta$ Number of Categories ${ }_{i(t)}$ & 2.219 & 1.787 \\
\hline Market Growth (t) & 1.250 & $.387 * * *$ \\
\hline$\Delta \mathrm{HHI}_{(\mathrm{t})}$ & .108 & .066 \\
\hline $\mathrm{R}^{2}$ & .380 & \\
\hline adj. $R^{2}$ & .350 & \\
\hline \multirow[t]{2}{*}{ Model 2 (modified) } & \multicolumn{2}{|c|}{ Sales Growth $\mathrm{i(t+1)}$} \\
\hline & Beta & S.E. \\
\hline$\Delta$ Purchase Intent $_{\mathbf{i}(t)}$ & 3.893 & $2.314^{*}$ \\
\hline Sales Growth ${ }_{i(t)}$ & -.536 & $.073 * * *$ \\
\hline$\Delta$ Average Selling Price ${ }_{i(t)}$ & -.267 & .489 \\
\hline$\Delta$ Number of Categories $i(t)$ & 2.432 & 1.811 \\
\hline Market Growth (t) & 1.261 & $.394 * * *$ \\
\hline$\Delta \mathrm{HHI}_{(\mathrm{t})}$ & .113 & $.068^{*}$ \\
\hline $\mathrm{R}^{2}$ & .361 & \\
\hline adj. $R^{2}$ & .331 & \\
\hline
\end{tabular}


sampling and operationalization approaches, our study validates and confirms the methodological concerns identified in prior NPS research (e.g., Grisaffe, 2007; Shaw, 2008). Fourth, we validate the current managerial practice of using NPS for predicting future sales growth as a measure of overall brand health (by capturing it for all potential customers) rather than as a measure of customer loyalty (e.g., Fitzgerald, 2017; Markey, 2014). Finally, we suggest an empirically-grounded, robust research methodology to consistently operationalize the relationship between NPS and future sales growth. In particular, NPS (1) can effectively predict only short-term sales growth, (2) should be operationalized as changes in NPS over time, and (3) should be used as a measure of brand health and tracked for all potential customers. These findings have implications for both academic researchers and managers, which we elaborate on subsequently.

\section{Theoretical implications}

Although there are exceptions (e.g., Pingitore et al., 2007; van Doorn et al., 2013), there has been little empirical support for Reichheld's (2003) claim that NPS predicts future sales growth, and others have found that NPS is not associated with sales growth at all (Keiningham, Cooil, Andreassen, \& Aksoy, 2007; Morgan \& Rego, 2006). Furthermore, Reichheld's (2003) research methodology has been strongly critiqued within academia (e.g., Grisaffe, 2007; Keiningham, Cooil, Andreassen, \& Aksoy, 2007; Sharp, 2008; Shaw, 2008). However, the research methodologies adopted in all other NPS studies to date are arguably subject to at least some of the same critiques as Reichheld's (2003) original work. The work presented here is to the best of our knowledge the first to have addressed all of these methodological issues. Furthermore, our results suggest that these methodological issues could be a potential reason why past research has come to contradictory conclusions regarding NPS.

More specifically, our study identified no bivariate correlations between NPS and sales growth. However, when we analyze longitudinal data using a random effects model, we find that changes in NPS are a significant predictor of future sales growth. Hence, the actual effect of NPS on sales growth could not be detected by using what has to date have been the most common NPS research analysis approach (e.g., Keiningham, Cooil, Andreassen, \& Aksoy, 2007; Pingitore et al., 2007; Reichheld, 2003). Of course, we do not claim that moving beyond the correlational analysis of Reichheld's (2003) work to the panel regression models used allows fullstrength claims of causality to be made. Nevertheless, we are able to supplement the simple concomitant variation of correlational analysis to add evidence of temporal precedence, which strengthens the causal interpretations of our findings in the spirit of the Granger causality tradition of precedence, or temporal relations (Granger, 2004; Granger \& Newbold, 1986).

Furthermore, we find that the optimal time lag between NPS and future sales growth is one quarter. However, it may be that the optimal time period may be industry related. In the case of the sportswear industry, a short repurchase cycle (Gruca \& Rego, 2005) is a likely explanation for the short time lag, particularly within the core market segment of 1630 year olds. These characteristics are typical of many related consumer goods industries, and thus we consider our findings in this area to be quite likely generalizable to other comparable contexts.

Our analysis also illustrates that the operationalization of NPS matters. Reichheld (2003) and other researchers used static levels of NPS but interpreted the results as referring to dynamic changes in NPS (Grisaffe, 2007). Using both levels and changes, we demonstrate that only changes in NPS are positively related to sales growth, but that static absolute levels of NPS are associated with future point levels of sales. This supports research by Rego et al. (2013) who found that changes in customer satisfaction can explain sales growth, but that levels of customer satisfaction predict future levels of sales and market share. Therefore, if researchers using NPS seek a predictor of future sales growth, they should analyze changes in NPS; but if they are interested in predicting levels of sales, they should focus on NPS levels.

Equally important are the findings on sample selection. Initially, NPS was conceived and used as a transaction-based customer loyalty measure, and was therefore only captured for current customers. However, practitioners (e.g., Fitzgerald, 2017; Markey, 2014) have since proposed that firms should implement NPS not only as a transaction-based tool, but should also track NPS for all potential customers, which makes NPS more akin to a measure of overall brand health. Indeed, this usage of NPS is considered by practitioners to be closely related to future sales growth (Fitzgerald, 2017). This is confirmed in our study: Our results show that only measuring NPS for all potential customers provides reliable predictions of sales growth. This is a crucial extension of the current academic knowledge on NPS, as to the best of our knowledge, academic studies to date have considered NPS to be a measure of loyalty and thus measured it for current customers only. According to our results though, the recommendation intent of non- and ex-customers carries valuable information about sales growth. Notably, this finding is not unique to NPS, as we also found that other customer mindset metrics such as brand awareness, brand consideration, and purchase intent are predictors of future sales growth when captured for all potential customers. Hence, researchers need to carefully consider their choice of assessing customer mindset metrics (e.g., NPS) for current or for all potential customers (similar to the suggestions by Katsikeas et al., 2016), in particular, when 
investigating the relationship between consumer mindset and sales growth, as we find that non-customers are an important source of sales growth, which has been suggested before in research (e.g., Ittner \& Larcker, 1998; Zeithaml et al., 2006).

\section{Managerial implications}

Our study demonstrates that under the right conditions, NPS predicts future sales growth, supporting existing managerial behavior. In doing so, our results provide a possible explanation for the continued popularity of NPS in managerial practice for more than 15 years, despite strong academic calls for its abandonment (e.g., Sharp, 2008). However, as evidenced in our study, managers need to be careful with how they utilize NPS, and they should pay particular attention to the following issues. First, given that NPS is most effective in predicting short-term sales growth, it is best considered as a measure that can validate whether recent marketing actions have had the desired effect on consumers. Nevertheless, in growing longterm sales, managers need to consider other factors which require more time to change, for example, their product positioning, distribution strategy and product range.

Second, our findings show that it is only changes in NPS that predict sales growth. Firms should therefore incentivize and communicate changes in NPS, rather than absolute NPS scores. Managers need to focus on improving NPS, and tracking this improvement, regardless of the NPS level itself.

Third, we show that firms should use NPS as a forwardlooking overall brand health metric, and track NPS for all potential customers. Our findings imply that brands cannot grow solely through the benefits associated with customer loyalty, such as retention (e.g., de Haan et al., 2015; Kristensen \& Eskildsen, 2014) or word-of-mouth (e.g., Leisen Pollack \& Alexandrov, 2013; Raasens \& Haans, 2017); they also need to attract additional new customers to nurture brand growth. In this sense, NPS can be seen as a general brand health indicator. However, it cannot be considered as a diagnostic tool to identify specific underlying problems, such as whether or not the brand is currently struggling with brand awareness, brand consideration or the satisfaction of current customers. NPS therefore can be considered by managers as akin to "taking the temperature" of their brand (Grisaffe, 2007); a simple, easy-to-administer and understandable diagnostic, which indicates the need for further investigation. Consequently, firms need to ensure that they are not only tracking NPS, but are also able to follow up with more specific diagnostics based on the NPS status identified (as a physician may follow up a high temperature reading with more specific tests), including exploring if the respondent is currently a customer, a former customer or has never purchased the brand. This also helps managers to make NPS more actionable which will guide them in increasing their NPS and ultimately future sales.
Nevertheless, NPS is certainly not the "one number you need to grow" (Reichheld, 2003, p. 46) and managers should be cautious regarding this claim for three reasons. First, as noted previously, NPS can only help to predict short-term sales growth. Second, like any other metric, NPS can explain only a fraction of future sales growth by itself: the model fit for Model 2 for brand health NPS increased only slightly (by .028) when compared with a model without NPS. Despite this, the impact of NPS is considerable in economic terms. An increase of one NPS point leads to sales growth of $1.458 \mathrm{pp}$. in the following quarter. Given that the average sales volume of the seven sportswear brands in the U.S. is \$3 billion per year, an increase of one NPS point can be translated into an increase of $\$ 44$ million in annual sales, or $\$ 11$ million per quarter. Third, extant literature suggests that NPS is most appropriately used in industries/segments with reasonably short interpurchase cycles (Gruca \& Rego, 2005) and where customers have a high emotional involvement in the purchase decision (Shaw, 2008). Therefore, managers must explore the significance of NPS in their own industry and organization. Our proposed research methodology will enable them to operationalize this effectively.

\section{Directions for future research}

NPS is one of the highest profile and most commonly used marketing metrics in practice (e.g., Kaplan, 2016; Safdar \& Pacheco, 2019), but it has received comparatively little academic validation, and the prevailing scholarly opinion towards NPS has been generally negative (Bendle et al., 2019). Our study demonstrates the potential utility of NPS in theory and practice and is therefore a first important step in reopening research on NPS. Managers will almost certainly continue to use NPS, and we believe that NPS should thus remain a part of the academic research agenda, in order that marketing scholarship may engage in meaningful conversations with managers on this key metric (Bendle et al., 2019). By considering our results and their limitations, we propose a future research agenda addressing five key directions (summarized in Table 8) including the generalizability of findings, predictors of future performance, antecedents of NPS, the role of non-customers, and the managerial usage of NPS.

First, while focusing on a single industry allowed us to develop a rich dataset and perform specific analyses facilitating new insights into NPS and its relationship with future sales growth, industry differences are common in relationships between customer mindset and firm performance (e.g., Gruca \& Rego, 2005; van Doorn et al., 2013). Future research scenarios should include studying NPS and its relationship with future sales growth in other industries which are either quite similar to the sportswear industry (to confirm our results) or which are very different, to explore Reichheld's (2003) claim that NPS has broad applicability. This research stream could eventually 
Table 8 Research agenda

(i) Generalizability of findings
Industry focus
- Is NPS a predictor of future sales growth in all consumer goods
industries or only in segments with high consumer involvement and
short interpurchase cycles?
- Is NPS a predictor of future sales growth in the service or durable
goods industries?
- Can these findings be generalized across industries and segments?
Time lags
- Can NPS predict long-term sales growth?
- Does the optimal time lag vary across industries?
- Is the optimal time lag tied to industry-specific interpurchase cycles?
Country focus
- Does NPS predict future sales growth across countries?
- Are local adaptions of NPS required to predict future sales growth?

(ii) Best predictor of future performance

NPS vs. other customer mindset metrics

- Is NPS the best predictor of future sales growth?

- Is NPS the best calculation methodology to obtain a customer mindset metric based on the likelihood-to-recommend question?

- Which other customer mindset metrics can span the customer journey and therefore be considered as "brand health metrics"?

\section{NPS and other firm performance dimensions}

- Does NPS predict growth or profitable growth?

- Is NPS a good indicator of other future firm performance dimensions such as profitability, cash flow or shareholder value?

\section{(iii) Antecedents of NPS}

- What determines how customers respond to the NPS question?

- How does this differ across customers and non-customers?

- Are the antecedents of NPS different to the antecedents of customer satisfaction or customer loyalty?

(iv) The role of non-customers

- Is it relevant to track customer mindset for former and never customers separately and should different metrics be used?

- Should brands prioritize regaining former customers or on acquiring completely new customers in order to grow?

\section{(v) Managerial usage of NPS}

- How should managers use NPS in practice, e.g., for target setting, employee remuneration, internal \& external communication, decision making or as a transactional loyalty measure?

- Are organizations that use NPS growing faster than their competitors?

reach a zenith in a cross-industry study controlling for industry differences by utilizing not only industry-specific but also sector-specific (e.g., services versus durable goods, versus consumer goods) control variables in the analysis. At the same time, it would be interesting to explore if NPS can predict long-term sales growth and if the optimal time lag varies by industries and if this is related to industry specific interpurchase cycles. Furthermore, as our results are based on U.S. data, extending the study to other countries would help to improve our understanding of the relationship between customer mindset and firm performance, and differences in measurement across borders (e.g., Kristensen \& Eskildsen, 2014; Zeithaml, 2000; van Doorn et al. (2013).

Second, while it is questionable that the validity of Reichheld's (2003) claim that NPS is the best predictor of sales growth can ever be definitively addressed, future research should extend our comparisons of NPS with other customer mindset metrics and sales growth. The use of other customer mindset metrics as brand health metrics could also be explored, by capturing metrics for all potential customers, and identifying which metrics should be collected for current customers. Further work could also address alternative methods of calculating NPS based on the likelihood to recommend question, to overcome the uncertainty associated with the original NPS calculation (Grisaffe, 2007; Kristensen \& Eskildsen, 2014). In addition, Reichheld (2003) also claimed that NPS would lead to profitable growth, suggesting that researchers need to test (1) the individual relationships between NPS and both sales growth and profitability, and (2) the relationship between increased NPS acquired by discounting sales prices (Bendle et al., 2019). Moreover, researchers could investigate the relationship between NPS and other firm performance metrics, such as cash flow and shareholder value, as managers also tend to assume a positive relationship between NPS and these metrics (Ramshaw, 2019).

Third, given the current lack of literature on the antecedents of NPS, future studies could explore both the precursors to NPS, and how they are either similar or different to the wellexplored antecedents of customer satisfaction (e.g., Anderson \& Sullivan, 1993) or loyalty (e.g., Dick \& Basu, 1994). Another angle on this idea could be to explore how these antecedents differ between current customers and non-customers.

Fourth, research on customer mindset metrics needs to address the importance of non-customers, especially as practitioners are reporting declining levels of loyalty (e.g., Hyken, 2019), highlighting the importance of customer acquisition in brands growth. This research should distinguish between never-users and former users of a brand, as these groups are at different stages of the customer journey. Emerging research questions in this field should address which customer mindset metrics should be employed to understand these different groups and if firms should prioritize one of the groups to foster their growth.

Finally, a growing consultancy industry (Bendle et al., 2019) helped to introduce NPS into many companies without a clear understanding as to how NPS should be used, or if it helps firm growth. Future research could address this gap by investigating (1) the relationship between different applications of NPS and firm performance and (2) if companies that utilize NPS outgrow their competition. 


\section{Conclusion}

Our study has dealt in detail with the prevailing academic critique on NPS. Whereas prior research on NPS has been subject to parts of the same critique as Reichheld's (2003) NPS study, our study is the first to address the critique holistically while also incorporating elements of NPS use in practice. Our results show that NPS can be a valid predictor of future sales growth under certain conditions, but they also confirm the validity of the methodological critiques of Reichheld's (2003) study. In particular, we find that changes in NPS have predictive value when forecasting sales growth in the near future and that NPS, in line with current managerial practice, should be used as a measure of brand health and not as a customer loyalty metric. We hope that our study provides managers with new insights on how to use NPS, and that it will also spark additional academic research on this key practitioner metric.

Acknowledgements The authors would like to thank Johannes Habel and Iman Ahmadi for their helpful suggestions on earlier versions of this manuscript, and also to acknowledge the contribution of the $\mathrm{AE}$ and reviewers in providing a number of extremely insightful suggestions for improvement. All errors and omissions remain the responsibility of the authors.

Open Access This article is licensed under a Creative Commons Attribution 4.0 International License, which permits use, sharing, adaptation, distribution and reproduction in any medium or format, as long as you give appropriate credit to the original author(s) and the source, provide a link to the Creative Commons licence, and indicate if changes were made. The images or other third party material in this article are included in the article's Creative Commons licence, unless indicated otherwise in a credit line to the material. If material is not included in the article's Creative Commons licence and your intended use is not permitted by statutory regulation or exceeds the permitted use, you will need to obtain permission directly from the copyright holder. To view a copy of this licence, visit http://creativecommons.org/licenses/by/4.0/.

\section{References}

Amemiya, T. (1971). The estimation of the variances in a variancecomponents model. International Economic Review, 12(1), 1-13.

Anderson, E. W., \& Sullivan, M. W. (1993). The antecedents and consequences of customer satisfaction for firms. Marketing Science, 12(2), 125-143.

Atefi, Y., Ahearne, M., Maxham, J. G., Donavan, D. T., \& Carlson, B. D. (2018). Does selective sales force training work? Journal of Marketing Research, 55(5), 722-737.

Baltagi, B. H. (2013). Economic analysis of panel data. John Wiley \& Sons Ltd.

Bandyopadhyay, S., \& Martell, M. (2007). Does attitudinal loyalty influence behavioral loyalty? A theoretical and empirical study. Journal of Retailing and Consumer Services, 14(1), 35-44.

Bell, A., Fairbrother, M., \& Jones, K. (2019). Fixed and random effects models: Making an informed choice. Quality and Quantity, 53, 1051-1074.
Bendle, N. T., Bagga, C. K., \& Nastasoiu, A. (2019). Forging a stronger academic-practitioner partnership - the case of net promoter score (NPS). Journal of Marketing Theory and Practice, 27(2), 210-226.

Bonett, D. G., \& Wright, T. A. (2000). Sample size requirements for estimating Pearson, Kendall and spearman correlations. Psychometrika, 65(1), 23-28.

Cohen, J. (1988). Statistical power analysis for the behavioral sciences. Lawrence Earlbaum Associates.

Court, D., Elzinga, D., Mulder, S., \& Vetvik, O. J. (2009). The consumer decision journey. The McKinsey Quarterly, 3, 1-11.

de Haan, E., Verhoef, P. C., \& Wiesel, T. (2015). The predictive ability of different customer feedback metrics for retention. International Journal of Research in Marketing, 32(2), 195-206.

Denning, S. (2011). Another Myth Bites the Dust: How Apple listens to its Customers, https://www.forbes.com/sites/stevedenning/2011/08/ 26/another-myth-bites-the-dust-how-apple-listens-to-its-customers. Accessed October 30, 2020.

Dick, A. S., \& Basu, K. (1994). Customer loyalty: Towards an integrated conceptual framework. Journal of the Academy of Marketing Science, 22(2), 99-113.

East, R., Romaniuk, J., \& Lomax, W. (2011). The NPS and the ACSI: A critique and an alternative metric. International Journal of Market Research, 53(3), 327-347.

Feng, H., Morgan, N. A., \& Rego, L. L. (2017). Firm Capabilites and growth: The moderating role of market conditions. Journal of the Academy of Marketing Science, 45, 76-92.

Fitzgerald, M. (2017). Net promoter: Implement the system. Maurice FitzGerald Consulting.

Granger, C. W. J. (2004). Time series analysis, Cointegration, and applications. American Economic Review, 94(3), 421-425.

Granger, C. W. J., \& Newbold, P. (1986). Forecasting economic time series. Academic Press.

Grisaffe, D. B. (2007). Questions about the ultimate question : Conceptual considerations in evaluating Reichheld's net promoter score. Journal of Consumer Satisfaction, Dissatisfaction \& Complaining Behavior, 20, 36-53.

Gruca, T. S., \& Rego, L. L. (2005). Customer satisfaction, cash flow, and shareholder value. Journal of Marketing, 69(3), 115-130.

Gupta, S., \& Zeithaml, V. A. (2006). Customer metric and their impact on financial performance. Marketing Science, 25(6), 718-739.

Habel, J., \& Klarmann, M. (2015). Customer reactions to downsizing: When and how satisfaction is affected? Journal of the Academy of Marketing Science, 43, 768-789.

Hanchane, S., \& Mostafa, T. (2012). Solving endogeneity problems in multilevel estimation: An example using education production functions. Journal of Applied Statistics, 39(5), 1101-1114.

Hyken, S. (2019). Customer Loyalty And Retention Are In Decline, https://www.forbes.com/sites/shephyken/2019/10/13/customerloyalty-and-retention-are-in-decline/. Accessed February 7, 2021.

Ittner, C. D., \& Larcker, D. F. (1998). Are nonfinancial measures leading indicators of financial performance? An analysis of customer satisfaction. Journal of Accounting Research, 36(supplement), 1-36.

Jacobson, R., \& Aaker, D. A. (1985). Is market share all that It's cracked up to be? Journal of Marketing, 49(4), 11-22.

Kaplan, J. (2016). The Inventor of Customer Satisfaction Surverys is Sick of them, too, https://www.bloomberg.com/news/articles/2016-0504/tasty-taco-helpful-hygienist-are-all-those-surveys-of-any-use. Accessed October 30, 2020.

Katsikeas, C. S., Morgan, N. A., Leonidou, L. C., \& Hult, G. T. M. (2016). Assessing performance outcomes in marketing. Journal of Marketing, 80(2), 1-20.

Keiningham, T. L., Cooil, B., Aksoy, L., Andreassen, T. W., \& Weiner, J. (2007). The value of different customer satisfaction and loyalty metrics in predicting customer retention, recommendation and share-ofwallet. Managing Service Quality, 17(4), 361-384. 
Keiningham, T. L., Cooil, B., Andreassen, T. W., \& Aksoy, L. (2007). A longitudinal examination of net promoter and firm revenue growth. Journal of Marketing, 71(3), 39-51.

Keiningham, T. L., Aksoy, L., Cooil, B., \& Andreassen, T. W. (2008). Net promoter, recommendations, and business performance: A clarification on Morgan and Rego. Marketing Science, 27(3), 531-532.

Kristensen, K., \& Eskildsen, J. (2014). Is the NPS a trustworthy performance measure? The TQM Journal, 26(2), 202-214.

Leisen Pollack, B., \& Alexandrov, A. (2013). Nomological validity of the net promoter index question. Journal of Services Marketing, 27(2), $118-129$.

Lemon, K. N., \& Verhoef, P. C. (2016). Understanding customer experience throughout the customer journey. Journal of Marketing, $80(6), 69-96$.

Markey, R. (2014). The Benefits of a Competitive Benchmark Net Promoter Score, https://www.bain.com/insights/the-benefits-of-acompetitive-benchmark-net-promoter-score. Accessed October 30, 2020.

Mecredy, P., Wright, M. J., \& Feetham, P. (2018). Are promoters valuable customers? An application of the net promoter scale to predict future customer spend. Australasian Journal of Marketing, 26, 3-9.

Morgan, N. A., \& Rego, L. L. (2006). The value of different customer satisfaction and loyalty metrics in predicting business performance. Marketing Science, 25(5), 426-439.

Ngobo, P. V. (2017). The trajectory of customer loyalty: An empirical test of Dick and Basu's loyalty framework. Journal of the Academy of Marketing Science, 45, 229-250.

Otto, A. S., Szymanski, D. M., \& Varadarajan, R. (2020). Customer satisfaction and firm performance: Insights from over a quarter century of empirical research. Journal of the Academy of Marketing Science, 48, 543-564.

Pauwels, K., \& van Ewijk, B. (2020). Enduring attitudes and contextual interest: When and why attitude surveys still matter in the online consumer decision journey. Journal of Interactive Marketing, 52, 20-34.

Pew Research Center. (2018). Percentage of Internet User by Age Groups, https://www.statista.com/statistics/266587. Accessed October 30, 2020.

Pingitore, G., Morgan, N. A., Rego, L. L., Gigliotti, A., \& Meyers, J. (2007). The single-question trap. Marketing Research, 19(2), 8-13.

Qualtrics (2020). Transactional vs. Relational NPS, https://www. qualtrics.com/uk/experience-management/customer/transactionalvs-relational-nps. Accessed October 30, 2020.

Raasens, N., \& Haans, H. (2017). NPS and online WOM: Investigating the relationship between Customer's promoter scores and eWOM behavior. Journal of Service Research, 20(3), 322-334.

Ramshaw, A. (2019). 34 Net Promoter Score Case Studies With Links to Business Value, https://www.genroe.com/blog/net-promoter-scoresuccess-stories-and-case-studies. Accessed October 30, 2020.

Rego, L. L., Morgan, N. A., \& Fornell, C. (2013). Reexamining the market share - customer satisfaction relationship. Journal of Marketing, 77(5), 1-20.
Reichheld, F. F. (2003). The one number you need to grow. Harvard Business Review, 81(12), 46-54.

Reichheld, F. F., \& Markey, R. (2011). The Ulimate question 2.0. HBR Press.

Rosnow, R. L., \& Rosenthal, R. (1996). Computing contrasts, effect sizes, and counternulls on other people's published data: General procedures for research consumers. Pyschological Methods, 1, $331-340$

Safdar, K. \& Pacheco, I. (2019). The Dubious Management Fad Sweeping Corporate America, https://www.wsj.com/articles/thedubious-management-fad-sweeping-corporate-america11557932084. Accessed October 30, 2020.

Sanchez, J., Abril, C., \& Haenlein, M. (2020). Competitive spillover elasticities of electronic word of mouth: An application to the soft drink industry. Journal of the Academy of Marketing Science, 48, 270-287.

Sharp, B. (2008). Net promoter score fails the test. Marketing Research, 20(4), 28-30.

Shaw, R. (2008). Net promoter. Journal of Database Marketing \& Customer Strategy Management, 15(3), 138-140.

Shi, Y., Lim, J. M., Weitz, B. A., \& France, S. L. (2018). The impact of retail format diversification on Retailers' Financial performance. Journal of the Academy of Marketing Science, 46, 147-167.

Sports \& Fitness Industry Association. (2018). Sports, fitness, and leisure activities topline participation report 2017. Sports \& Fitness Industry Association.

van Doorn, J., Leeflang, P. S. H., \& Tijs, M. (2013). Satisfaction as a predicator of future performance: A replication. International Journal of Research in Marketing, 30(3), 314-318.

Wallace, T. D., \& Hussain, A. (1969). The use of error components models in combining cross section with time series data. Econometrica, 37(1), 55-72.

Williams, P., \& Naumann, E. (2011). Customer satisfaction and business performance: A firm-level analysis. Journal of Services Marketing, 25(1), 20-32.

Zeithaml, V. A. (2000). Service quality, profitability, and the economic worth of customers: What we know and what we need to learn. Journal of the Academy of Marketing Science, 28, 67-85.

Zeithaml, V. A., Bolton, R. N., Deighton, J., Keiningham, T. L., Lemon, K. N., \& Petersen, J. A. (2006). Forward-looking focus: Can firms have adaptive foresight. Journal of Service Research, 9(2), 168183.

Zhou, C., Sridhar, S., Becerril-Arreola, R., Cui, T. H., \& Dong, Y. (2019). Promotions as competitive reactions to recalls and their consequences. Journal of the Academy of Marketing Science, 47, 702722.

Publisher's note Springer Nature remains neutral with regard to jurisdictional claims in published maps and institutional affiliations. 